\title{
Impacts of management practices on soil organic carbon in degraded alpine meadows on the Tibetan Plateau
}

\author{
X. F. Chang ${ }^{1,2, *}$, X. X. Zhu ${ }^{3,4, *}$, S. P. Wang ${ }^{1}$, S. J. Cui ${ }^{3,4}$, C. Y. Luo ${ }^{3}$, Z. H. Zhang ${ }^{3}$, and A. Wilkes ${ }^{5}$ \\ ${ }^{1}$ Laboratory of Alpine Ecology and Biodiversity of the Institute of Tibetan Plateau Research, Chinese Academy of Sciences, \\ 16 Lincui Rd., 100101 Beijing, China \\ ${ }^{2}$ State Key Laboratory of Soil Erosion and Dryland Farming on Loess Plateau, Institute of Soil and Water Conservation, \\ Northwest A\&F University, 26 Xinong Rd., 712100 Yangling, China \\ ${ }^{3}$ Key Laboratory of Adaptation and Evolution of Plateau Biota, Haibei Alpine Meadow Ecosystem Research Station, \\ Northwest Institute of Plateau Biology, Chinese Academy of Sciences, 23 Xinning Rd., 810008 Xining, China \\ ${ }^{4}$ Graduate University, Chinese Academy of Sciences, 19A Yuquan Rd., 100049 Beijing, China \\ ${ }^{5}$ Center for Mountain Ecosystem Studies, Kunming Institute of Botany of the Chinese Academy of Sciences, 132 Lanhei Rd., \\ 650201 Kunming, China \\ *These authors contribued equally to this work.
}

Correspondence to: S. P. Wang (wangsp@itpcas.ac.cn)

Received: 2 November 2013 - Published in Biogeosciences Discuss.: 8 January 2014

Revised: 2 April 2014 - Accepted: 30 May 2014 - Published: 3 July 2014

\begin{abstract}
Grassland soil organic carbon (SOC) is sensitive to anthropogenic activities. Increased anthropogenic disturbance related to overgrazing has led to widespread alpine grassland degradation on the Tibetan Plateau. The degraded grasslands are considered to have great potential for carbon sequestration after adoption of improved management practices. Here, we calibrated and employed the Century model to investigate the effects of overgrazing and improved managements on the SOC dynamics in alpine meadows. We calibrated the Century model against plant productivity at the Haibei Research Station. SOC stocks for validation were obtained in 2009-2010 from degraded alpine meadows in two communes. We found that Century model can successfully capture grassland SOC changes. Overall, our simulation suggests that degraded alpine meadow SOC significantly increased with the advent of restoration management from 2011 to 2030. Carbon sequestration rates ranged between $0.04 \mathrm{Mg} \mathrm{Cha}^{-1} \mathrm{yr}^{-1}$ in lightly degraded winter grazing grasslands and $2.0 \mathrm{MgCha}^{-1} \mathrm{yr}^{-1}$ in moderately degraded summer grazing grasslands. Our modelling work also predicts that improve management in degraded Tibetan grasslands will contribute to an annual carbon sink of $0.022-0.059 \mathrm{Pg} \mathrm{Cyr}^{-1}$. These results imply that restoration of degraded grasslands in the Tibetan Plateau has great po-
\end{abstract}

tential for soil carbon sequestration to mitigate greenhouse gases.

\section{Introduction}

Grassland soils play a critical role in stabilizing or reducing atmospheric carbon, as they occupy about a quarter of the world's land surface and store $10 \%$ of global carbon storage (Scurlock et al., 2002). It has been documented that extensive areas of grassland have suffered some degradation (Harris, 2010; Kemp et al., 2013). Losses in soil organic carbon (SOC) by degradation have been large, undoubtedly affecting the terrestrial greenhouse gas balance. Alpine grasslands on the Tibetan Plateau, accounting for over $60 \%$ of the total plateau area, have been grazed for millennia (Yang et al., 2008; Harris, 2010). Due to increased disturbance from livestock populations over the last $50 \mathrm{yr}$ (Harris, 2010; Miehe et al., 2008), one third of alpine grasslands were in a degraded state in 1990s (Duan et al., 2013). The degradation of the Tibetan grasslands has led to the loss of $1.01 \mathrm{Pg}$ of soil carbon since the 1980s, which is more than twice of potential carbon accumulation due to climate change and elevated $\mathrm{CO}_{2}$ concentration (Xie et al., 2007). Alternatively, degraded 
grassland soils may have substantial potential for sequestering carbon through improving management practices, which weaken or even reverse negative effects of overgrazing. Evidence from early observational studies has agreed on the promoted grassland productivity and soil carbon replenishment after adoption of improved management practices (Wang et al., 2011). Guo et al. (2008) estimated that the adoption of an improved management practice could potentially sequester $15.24-65.75 \mathrm{Mg} \mathrm{Cha}^{-1}$ in degraded alpine grassland soils. However, the magnitude of this potential sinks varies markedly among management practices (Wang et al., 2011; Guo et al., 2008). Characterizing management practices on the SOC stock has important implications for mitigation policies designed to absorb anthropogenic $\mathrm{CO}_{2}$ emissions.

Quantifying the potential of SOC sequestration is a great challenge due to temporal and spatial heterogeneity of soil properties, environmental conditions, management history, and other complex interactions between these components (Yang et al., 2009; Luo and Weng, 2011). Extrapolation of site-specific results to other soil and climate often leads to great uncertainty. However, simulation models are essential to integrate data from long-term experiments and process studies together with information from spatial-scale surveys, which can overcome the extrapolating limitations (Luo and Weng, 2011). Additionally, models have flexibility to simulate various management practices, such as grazing, tillage, and fertilization (Xu et al., 2010; Wang et al., 2008). During the past decades, several types of models have been widely applied to simulate the regional carbon cycle on the Tibetan Plateau, such as the TEM (terrestrial ecosystem model), Century, BIOME-BGC (Biome-BioGeochemical Cycles) and ORCHIDEE (Organizing Carbon and Hydrology in Dynamic Ecosystems; Tan et al., 2010; Zhang et al., 2007; Zhuang et al., 2010). However, the application of these generic carbon cycle models suffers from a lack of systematic calibration and validation against observations due to limited filed experiments (Tan et al., 2009). Moreover, these modelling studies that evaluated the carbon cycle over the plateau neglected human disturbances and grazing influences (Zhang et al., 2007; Piao et al., 2012). Considering extensive area of degraded grasslands and great potential for carbon sequestration on the Tibetan Plateau, there is a need for understanding the impact of management practices on SOC pools.

In this study, we applied the widely used process-based Century model to evaluate the SOC response to human disturbances and grazing influences in Tibetan alpine grasslands. The model parameterizations were calibrated using plant productivity measurements at an alpine meadow site. Soil profile data sampled from the Tangde and Xiala communes in Zeku County was used to validate the simulated soil carbon at depleted state due to overgrazing. We then used the verified Century model to conduct simulations on SOC response to typical restoration management on the Tibetan Plateau, and to quantify the uncertainty of SOC sequestration.

\section{Materials and methods}

\subsection{Study area}

The study area spread over approximately $1.9 \times 10^{4}$ ha in the boundaries of Tangde and Xiala villages in Zeku County, Qinghai Province, China. The altitude varies from 3400 to $4100 \mathrm{~m}$. The mean annual temperature is about -2 to, $2.3^{\circ} \mathrm{C}$. The mean annual precipitation is $460 \mathrm{~mm}$ (Table 1). Alpine meadow was the dominant vegetation type, which consists of Kobresia pygmaea (C.B. Clarke), K. humilis (C.A. Mey) Serg., and $K$. tibetica Maxim. The growing season normally starts in mid-May and lasts until mid-September. The soil is classified as alpine meadow soil or Mat Cry-gelic Cambisols (the Chinese soil taxonomy). Pastoralism has been the dominant land use in this area for several centuries. Livestock numbers have increased during the last 50-60 yr. At the same time, alpine meadows in this area have degraded, with characteristics of vegetation coverage and productivity decrease, soil fertility change, and soil loss.

\subsection{Soil sampling and analyses}

Soil samples were collected in late August through early September of 2009 and 2010, with 591, 204, 121 and 280 sites for lightly, moderately, heavily and extremely degraded summer grazing grassland, respectively. At each sampling site, five cores were extracted for depth intervals of $10 \mathrm{~cm}$ to a depth of $20 \mathrm{~cm}$, and pooled in the field by depth. The soil samples were air-dried, processed to remove visible plant residue and then sieved ( $2 \mathrm{~mm}$ mesh) for further analysis. Soil bulk density was determined with core cutters $\left(100 \mathrm{~cm}^{3}\right.$, diameter $5.3 \mathrm{~cm}$ ). SOC concentration was measured using a Shimadzu SOC-5000 analyser (Shimadzu corp., Kyoto, Japan). Soil texture was determined by a particle size analyser (MasterSizer, 2000). Soil pH was measured using a pH meter in soil water suspension, with a soil: water ratio of $1: 2.5$. Soil carbon concentrations were converted to areal estimates for 0-20 cm depth using soil bulk density for each site.

\subsection{Century model simulations}

\subsubsection{Century model}

The Century model is a highly integrated process-based ecosystem model that calculates plant growth and variations of carbon and nutrient on a monthly basis. The model consists of three major coupled modules for vegetation processes, exchange of water and energy and terrestrial carbon cycle. It partitions soil organic matter into active pool, slow pool and passive pool with turnover times of 1-15, 20-40 and 200-15000 yr, respectively. The Century model has been used extensively to simulate the fluxes and storage of carbon in various terrestrial ecosystems that are driven by multiple 
Table 1. Site parameters at the Haibei Research Station and the study area.

\begin{tabular}{lll}
\hline Site parameter & Haibei Station & Zeku County \\
\hline Location & $37^{\circ} 36^{\prime} \mathrm{N}, 101^{\circ} 18^{\prime} \mathrm{E}$ & $35^{\circ} 14^{\prime} \mathrm{N}, 101^{\circ} 15^{\prime} \mathrm{E}$ \\
Altitude (m a.s.l.) & 3200 & 3680 \\
Soil texture (clay, silt, sand) $(\%)$ & $0.24,0.39,0.37$ & $0.27,0.38,0.35$ \\
Bulk density $\left(\mathrm{g} \mathrm{cm}^{-3}\right)$ & 0.93 & 0.89 \\
Soil pH & 7.5 & 7.0 \\
Minimum mean monthly temperature $\left({ }^{\circ} \mathrm{C}\right)$ & -6.0 & -8.0 \\
Maximum mean monthly temperature $\left({ }^{\circ} \mathrm{C}\right)$ & 9.5 & 6.7 \\
Mean precipitation $(\mathrm{mm})$ & 522.2 & 448.8 \\
Vegetation type & Alpine meadow \\
Soil type & Mat Cry-gelic Cambisols \\
\hline
\end{tabular}

Climate parameters were averaged from 1960 to 2005, and from 1991 to 2000 in the Haibei Research station and study area, respectively.

natural and anthropogenic perturbations (e.g. climate change, $\mathrm{CO}_{2}$ concentration, and land use and management practices).

Grazing events can be realistically simulated in the Century model by removing the defined fraction of aboveground live and standing dead plant material each month. The model has three options as proxy of grazing influences (Feng and Zhao, 2011): option 1, there are no direct impacts of grazing on plant production; option 2 refers to light grazing with a constant root: shoot carbon allocation ratio and a linear decrease in potential plant production with increasing grazing intensity; option 3 represents moderate and heavy grazing where aboveground plant production increases for moderate grazing and decreases sharply for heavy grazing. The root : shoot carbon allocation ratio is constant for low to moderate grazing and sharp decreases for heavy grazing. The century model could also simulate other human disturbances such as fertilization and tillage. More detailed information about the model structure and processes can be found in previous studies (Feng and Zhao, 2011; Zhang et al., 2007).

\subsubsection{Model calibration}

Model calibration was performed on an alpine meadow field at the Haibei Research Station, Chinese Academy of Science. The sample field has been fenced since 1980, which had been used for winter free grazing (November-May). Climate change and vegetation dynamics then have been monitored each year. Monthly precipitation, maximum and minimum temperature were measured with an automatic weather station (Table 1). Aboveground plants were cut in 10-20 quadrants of $50 \mathrm{~cm} \times 50 \mathrm{~cm}$ during the growing season and aboveground biomass was measured using the weighing method. The aboveground biomass of the sample field was the average value of the quadrants. In calibration, aboveground biomass dynamic and monthly meteorological data were provided by the Haibei Research Station. Century was calibrated by iteratively running the model to equilibrium for $5000 \mathrm{yr}$ (from 3020 BC to 1980) with the initial grazing intensity of
$50 \%$ (50\% of live shoots was removed by grazing event per month). Starting from this equilibrium state, we simulated a fenced scenario (exclosure from grazing) in the Century management schedules. The model was integrated for the 1998-2007 period, forced by observed weather data. We then inspected the simulated outputs and altered the vegetation parameters until the aboveground biomass matched the measured values. First, we changed the effect of temperature on plant growth which depends on monthly mean temperature. The mean annual aboveground net primary productivity (NPP) and belowground NPP are of $0.12 \pm 0.33$ and $0.23 \pm 0.04 \mathrm{~kg} \mathrm{C} \mathrm{m}^{-2}$, respectively (Zhao et al., 2009). To attain these values, we then adjusted the aboveground potential monthly production parameter PRDX (1) and carbon allocation parameters. We also compared the shoot-to-root biomass ratios against observed data for the alpine meadow field. In addition, we adjusted the effect of annual precipitation on atmospheric $\mathrm{N}$ fixation by changing the intercept value, i.e. EPNFA (1), and the slop value, i.e. EPNFA (2), as suggested by Fang et al. (unpublished data). The parameters are listed in the Supplement Table S1.

\subsubsection{Model validation}

We validated the model output with a set of SOC observations obtained from our study area independent of the calibration phase. We kept the model adjustments described as "model calibration" and only modified the model schedule and site variables. Weather data necessary for running the model were obtained from the meteorological station at Zeku County, about $40 \mathrm{~km}$ from the study area. A general representative grassland management scenario was developed for the region based on published historical accounts, farm census and farmer interviews. Livestock numbers have increased in the early 1960s in the study area. Thus, grassland management practices were divided into two categories, corresponding periods of 0-1960 as summer-free grazing (JuneOctober) with $50 \%$ intensity and 1960-2010 as overgrazing 
with $55,65,80,95 \%$ intensities for light, moderate, heavy and extreme grazing, respectively. Soil carbon stocks from the consecutive field surveys during 2009-2010 were averaged and used to assess model performance in 2010.

\subsubsection{Simulation protocol}

A series of management scenarios related to grazing and restoring were adopted in the modelling. In simulations S1S6, grazing intensities were varied for lightly and moderately degraded states, and in simulations S7 and S8 for heavily and extremely degraded states; artificial pasture will be established accompanied with fertilization (Table 2). The nitrogen fertilizer amounts used were based on nutrient recommendations for alpine meadow soils. These simulated practices have been adopted since passing the latest Grassland Law in 2002 and will be expanded on the Tibetan Plateau in the future. We also considered two sets of grazing management, the winter grazing and summer grazing, which are prevalent on the plateau. In the simulations, for purposes of brevity, site variables were averaged for degraded states with broadly similar grazing management.

\subsubsection{Modelling uncertainty}

The CDM EB (Clean Development Mechanism Executive Board)-approved General Guidelines For Sampling And Surveys For Small-Scale CDM Project Activities ${ }^{14}$ with a view to reducing the uncertainty of model input parameters. As depicted in Methodology for Sustainable Grassland Management ( $S G M)$, we estimated uncertainty using the model inputs with the upper and lower limits of the $95 \%$ confidence level. The range of modelling response demonstrates the uncertainty of the soil modelling. First, SOC sequestration estimates were computed using the minimum and maximum values of the model input; then, a percentage uncertainty was estimated based on half of the range divided by the SOC sequestration induced by the mean values of the model input. Following the proposed SGM methodology, we set a tolerable uncertainty of $30 \%$ for carbon sequestration. In this uncertainty analyses, climate and soil model parameters (mean maximum and minimum air temperature, precipitation, soil texture, soil bulk density and $\mathrm{pH}$ ) were considered simultaneously with the assumption of a normal distribution. Finally, projected sequestration was adjusted with the modelling uncertainty. If the modelling uncertainty is $15 \%$ or less, SOC sequestration estimates were reported without any adjustments.
Table 2. Scheduling of management practices in the Century model for Zeku County.

\begin{tabular}{|c|c|c|}
\hline Scenario & Period & Management practice \\
\hline \multirow[t]{2}{*}{ S1 } & 2011-2020 & Graz: Jun-Oct; $45 \%$ \\
\hline & 2021-2030 & Graz: Jun-Oct; $50 \%$ \\
\hline $\mathrm{S} 2$ & $2011-2030$ & Graz: Nov-Apr; $50 \%$ \\
\hline \multirow{2}{*}{$\mathrm{S} 3$} & 2011-2020 & Graz: Jun-Oct; $30 \%$ \\
\hline & $2021-2030$ & Graz: Jun-Oct; $50 \%$ \\
\hline \multirow{2}{*}{$\mathrm{S} 4$} & 2011-2020 & Graz: Nov-Apr; $40 \%$ \\
\hline & $2021-2030$ & Graz: Nov-Apr; $50 \%$ \\
\hline \multirow[t]{7}{*}{ S5 } & 2011 & Cultivation: No-till drill \\
\hline & & Graz: Nov-Apr; $50 \%$ \\
\hline & 2012-2014 & Graz: Nov-Apr; $50 \%$ \\
\hline & 2015 & $\begin{array}{l}\text { Fertilizer: } 15 \mathrm{~g} \mathrm{~N} / \mathrm{m} 2 \text { in Jul } \\
\text { Graz: Nov-Apr; } 50 \%\end{array}$ \\
\hline & 2016-2024 & Graz: Nov-Apr; $50 \%$ \\
\hline & 2025 & $\begin{array}{l}\text { Fertilizer: } 15 \mathrm{~g} \mathrm{~N} \mathrm{~m}^{-2} \text { in Jul } \\
\text { Graz: Nov-Apr; } 50 \%\end{array}$ \\
\hline & 2026-2030 & Graz: Nov-Apr; $50 \%$ \\
\hline \multirow[t]{8}{*}{ S6 } & 2011 & $\begin{array}{l}\text { Cultivation: plowing; cultivator } \\
\text { Fertilizer: } 15 \mathrm{~g} \mathrm{~N} \mathrm{~m}^{-2} \text { in May }\end{array}$ \\
\hline & 2012-2014 & Graz: Nov-Apr; $50 \%$ \\
\hline & 2015 & $\begin{array}{l}\text { Fertilizer: } 15 \mathrm{~g} \mathrm{~N} \mathrm{~m}^{-2} \text { in Jul } \\
\text { Graz: Nov-Apr; } 50 \%\end{array}$ \\
\hline & 2016-2020 & Graz: Nov-Apr; $50 \%$ \\
\hline & 2021 & $\begin{array}{l}\text { Cultivation: plowing; cultivator } \\
\text { Fertilizer: } 15 \mathrm{~g} \mathrm{~N} \mathrm{~m}^{-2} \text { in May }\end{array}$ \\
\hline & $2022-2024$ & Graz: Nov-Apr; $50 \%$ \\
\hline & 2025 & $\begin{array}{l}\text { Fertilizer: } 15 \mathrm{~g} \mathrm{~N} \mathrm{~m}^{-2} \text { in Jul } \\
\text { Graz: Nov-Apr; } 50 \%\end{array}$ \\
\hline & 2026-2030 & Graz: Nov-Apr; $50 \%$ \\
\hline \multirow[t]{2}{*}{ S7 } & 2011-2020 & Graz: Nov-Apr; $45 \%$ \\
\hline & 2021-2030 & Graz: Nov-Apr; $50 \%$ \\
\hline \multirow[t]{2}{*}{ S8 } & $2011-2020$ & Graz: Nov-Apr; $40 \%$ \\
\hline & 2021-2030 & Graz: Nov-Apr; $50 \%$ \\
\hline
\end{tabular}

\section{Results}

\subsection{Model calibration and validation}

After the model parameter adjustments were accomplished by simulating grassland management scenarios according to the conditions of the long-term experiment at the Haibei Research Station, we checked the consistency between the modelled evolution of productivity and measurements from 1998 to 2010 (including six data sets measured in MarchAugust 2003). A significant linear relationship $(p<0.001)$ was found between measured and modelled aboveground biomass with $r^{2}$ of 0.89 and RMSE (root mean square error) of $17.52 \%$, showing that the model could moderately simulate productivity dynamics of alpine meadow (Fig. 1). The simulated SOC stock $\left(10.39 \mathrm{~kg} \mathrm{C} \mathrm{m}^{-2}\right)$ was similar to the value measured in 1999 (10.35 $\mathrm{kg} \mathrm{C} \mathrm{m}^{-2}$, Zhang et al., 2003). As explained earlier, we applied the site-specific SOC inventory in summer grazing grasslands for validation of the 


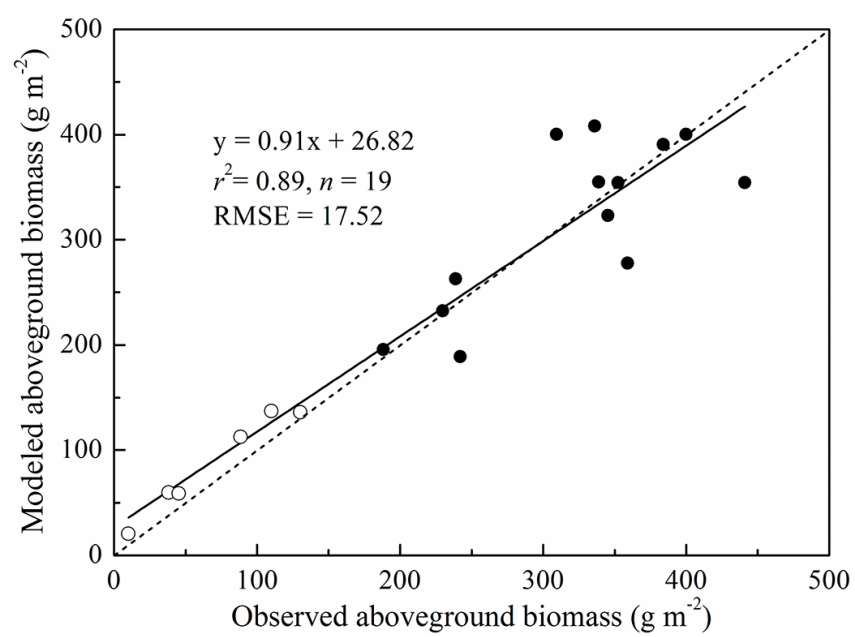

Figure 1. Comparison of observed and modelled aboveground biomass of alpine meadow at the Haibei Research Station in the Tibetan Plateau for the 1998-2010 period. If the six biomass data sets measured in March-August 2003 (open circles) were excluded, observed aboveground biomass were significantly correlated with the corresponding simulated values $\left(y=0.86 x+56.52, r^{2}=0.60\right.$, $p=0.002 ; \operatorname{RMSE}=15.45)$

optimized model. The Century model produced a relatively high error in simulating the Zeku County conditions, with light, moderate, heavy and extreme degradation RMSEs of $10.04,12.01,11.20$ and $12.01 \%$, respectively (Fig. 2). Given the large heterogeneity at the field scale, this degree of agreement between soil carbon measurements and model values was considered acceptable.

\subsection{SOC response to improved managements}

Significant increases in SOC stocks were noted after adoption of improved management such as fertilizer application, reduced grazing intensity, altered grazing timing and cultivated pasture from 2011 onwards. Although simulated SOC dynamics showed similar trajectories among degraded grasslands with varying degrees, the magnitude was largely variable (Figs. 3, 4). A larger increase in soil carbon could be predicted for original summer grazing grassland with a more degraded state. For example, simulation $\mathrm{S} 1$ predicted that annual SOC in summer grazing grassland has increased $0.60 \mathrm{Mg} \mathrm{Cha}^{-1} \mathrm{yr}^{-1}$ in the project period 2011-2030, while only $0.04 \mathrm{Mg} \mathrm{Cha}^{-1} \mathrm{yr}^{-1}$ in winter grazing grassland in a lightly degraded state (Table 3 ). Similarly, the modelled SOC accrual rate was higher in the summer than in the winter grazing grasslands in moderate, heavy and extreme initial degradation states, respectively, even adopting the same restoration trials (S3, S5 and S6, Table 3). In general, lower SOC sequestration rates were found in less degraded as compared with highly degraded grassland states. The simulation S4 in the summer grazing grassland in moderate degradation state had the greatest sequestration rate, whereas the

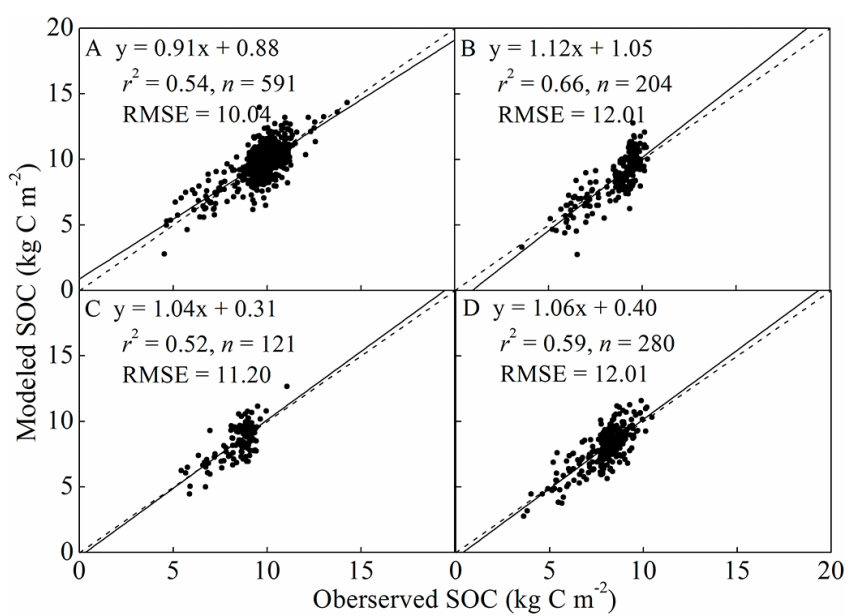

Figure 2. Comparisons of observed and modelled grassland SOC stocks for (A) lightly, (B) moderately, (C) heavily (D) and extremely degraded states, respectively.

lowest rate was observed in simulation S1 for lightly degraded winter grazing grassland. The summer grazing grassland soils were projected (2011-2030) to sequester 12.03$21.44 \mathrm{Mg} \mathrm{Cha}^{-1}$ for light, $38.42-40.08 \mathrm{Mg} \mathrm{Cha}^{-1}$ for moderate, $37.57 \mathrm{Mg} \mathrm{Cha}^{-1}$ for heavy and $38.59 \mathrm{Mg} \mathrm{Cha}^{-1}$ for extreme degradation states, respectively, while for the winter grazing grassland these were $0.75-0.99,3.21-7.51,6.88$ and $8.58 \mathrm{Mg} \mathrm{Cha}^{-1}$, correspondingly. The projected uncertainties were $4.31-28.93 \%$.

\section{Discussion}

\subsection{Overgrazing causing SOC losses}

Our modelling analysis showed a considerable reduction in SOC in the overgrazing periods from 1960 to 2010. The loss of native stocks was approximately 18, 37, 38 and $40 \%$ in lightly, moderately, heavily and extremely degraded summer grazing grasslands, respectively. Recently, a meta-analysis of data from alpine grasslands concluded that lightly, moderately and severely degraded pastures lost $(27 \pm 8) \%$, (49 $\pm 4) \%$ and $(55 \pm 3) \%$, respectively, of SOC stocks in the non-degraded pasture (Huang et al., 2010). Several field experiments on the Tibetan Plateau revealed that SOC in lightly degraded grasslands was comparable to intact grassland, with its SOC varying from 90 to $102 \%$ of the SOC in intact grasslands, while moderately and heavily grazed grasslands demonstrated a significant decrease in SOC content of 77 $91 \%$ (Pei, 2004; Wang et al., 2007). The difference in carbon losses between studies may be in part due to the significant differences in soil texture. Coarse, sandy soils are less resistant to wind and rainfall than finer textured soils; therefore the greater losses are reported for coarse textured soils (Batlle-Bayer et al., 2010; McSherry and Ritchie, 2013). 
Table 3. Soil carbon sequestration of degraded grasslands under different management practices.

\begin{tabular}{|c|c|c|c|c|c|c|c|c|}
\hline \multicolumn{2}{|c|}{ Present condition } & $\begin{array}{c}\text { Management } \\
\text { practice }\end{array}$ & $\begin{array}{c}\mathrm{SOC}_{2010} \\
\left(\mathrm{~kg} \mathrm{C} \mathrm{m}^{-2}\right)\end{array}$ & \multirow{2}{*}{$\begin{array}{c}\mathrm{SOC}_{2030} \\
\frac{\left(\mathrm{kg} \mathrm{C} \mathrm{m}^{-2}\right)}{12.17}\end{array}$} & \multirow{2}{*}{$\begin{array}{c}\text { SOC } \\
\begin{array}{c}\text { sequestration } \\
\left(\mathrm{MgC} \mathrm{ha}^{-1}\right)\end{array} \\
12.03\end{array}$} & \multirow{2}{*}{$\begin{array}{c}\begin{array}{c}\text { Modelling } \\
\text { uncertainty } \\
(\%)\end{array} \\
4.31\end{array}$} & \multirow{2}{*}{$\begin{array}{c}\begin{array}{c}\text { Modified SOC } \\
\text { sequestration } \\
\left(\mathrm{MgCha}^{-1}\right)\end{array} \\
12.03\end{array}$} & \multirow{2}{*}{$\begin{array}{l}\text { SOC sequestration } \\
\text { rate } \\
\left(\mathrm{Mg} \mathrm{Cha}^{-1} \mathrm{yr}^{-1}\right) \\
0.60\end{array}$} \\
\hline Summer & $\mathrm{L}$ & S1 & 10.97 & & & & & \\
\hline grassland & & $\mathrm{S} 2$ & 10.97 & 13.11 & 21.44 & 5.24 & 21.44 & 1.07 \\
\hline & M & $\mathrm{S} 3$ & 8.43 & 12.89 & 44.63 & 28.93 & 38.42 & 1.92 \\
\hline & & $\mathrm{S} 4$ & 8.43 & 12.95 & 45.26 & 26.43 & 40.08 & 2.00 \\
\hline & $\mathrm{H}$ & S5 & 8.30 & 12.45 & 41.47 & 24.41 & 37.57 & 1.88 \\
\hline & $\mathrm{S}$ & S6 & 8.02 & 12.47 & 44.57 & 28.42 & 38.59 & 1.93 \\
\hline \multirow{6}{*}{$\begin{array}{l}\text { Winter } \\
\text { grassland }\end{array}$} & $\mathrm{L}$ & S7 & 13.08 & 13.18 & 0.99 & 8.92 & 0.99 & 0.05 \\
\hline & & $\mathrm{S} 1$ & 13.09 & 13.16 & 0.75 & 10.25 & 0.75 & 0.04 \\
\hline & M & S8 & 11.58 & 12.35 & 7.70 & 17.42 & 7.51 & 0.38 \\
\hline & & $\mathrm{S} 3$ & 11.58 & 11.92 & 3.37 & 19.53 & 3.21 & 0.16 \\
\hline & $\mathrm{H}$ & S5 & 11.12 & 11.82 & 7.05 & 17.35 & 6.88 & 0.34 \\
\hline & $\mathrm{S}$ & S6 & 11.08 & 11.98 & 9.03 & 19.94 & 8.58 & 0.43 \\
\hline
\end{tabular}

L, M, H and S represent the lightly, moderately, heavily and severely degraded alpine meadows, respectively. SOC 2010 , SOC 2030 : SOC stocks in 2010 and 2030 . SOC sequestration was calculated as the difference between $\mathrm{SOC}_{2030}$ and $\mathrm{SOC}_{2010}$. Modified SOC sequestration was an adjusted estimate of SOC sequestration based on SAGM methodology. S1-S8 were demonstrated in detail in Table 2.

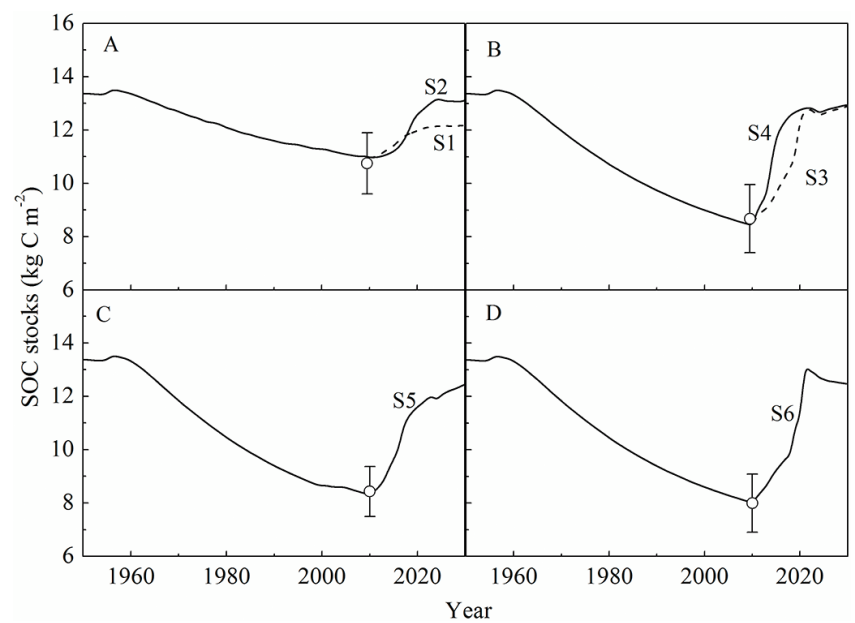

Figure 3. Soil organic carbon trajectory of the (A) lightly, (B) moderately, $(\mathbf{C})$ heavily and $(\mathbf{D})$ extremely degraded summer grazing grasslands as simulated by the Century model. Dots represent averaged SOC stocks measured in 2009-2010 and bars are standard deviations. Simulations S1-S6 correspond to scenarios from Table 2.

Such SOC loss may also vary according to the local climate. The relatively greater precipitation-simulated organic matter decomposition, thus amplified the negative effects of overgrazing (McSherry and Ritchie, 2013).

\subsection{SOC sequestration of degraded alpine grasslands}

All improved management practices increased soil carbon over the project period (2011-2030). The magnitude of soil carbon sequestration depended on management practices as well as initial seasonal utilization systems (summer or winter

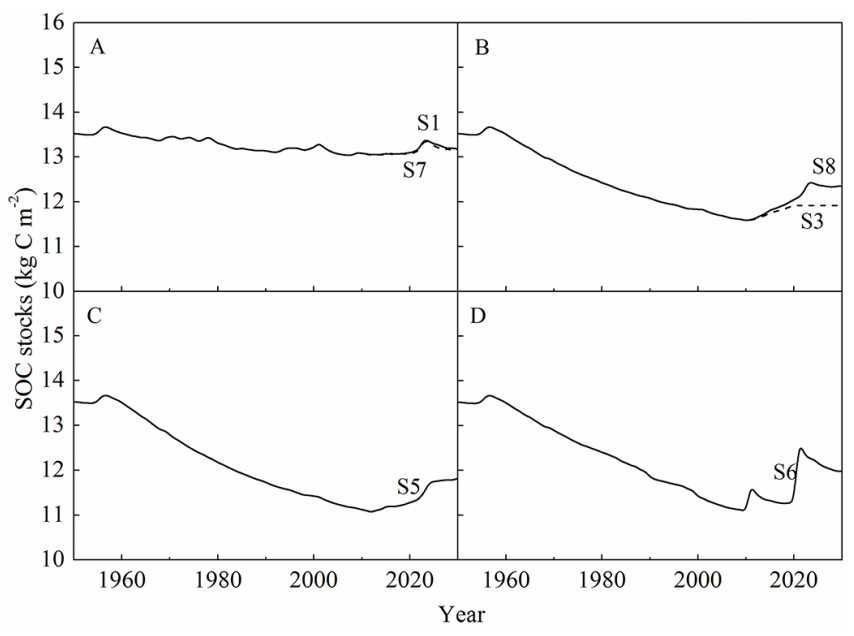

Figure 4. Soil organic carbon trajectory of the (A) lightly, (B) moderately, (C) heavily and (D) extremely degraded winter grazing grasslands as simulated by the Century model. Simulations S1, S3 and S5-S8 correspond to scenarios from Table 2.

grazing) and degraded states. One underlying "carbon saturation" mechanism may dictate these patterns (Conant et al., 2001). Initial SOC was identified as the predominant environmental variable that negatively influenced SOC sequestration (Zhao et al., 2013). Recent work in grasslands suggests that larger accumulation was found in soils with low initial carbon and less in soils with initial high carbon stocks (Wang et al., 2011). In our study, carbon sequestration in more severe degradation states was larger than in lesser degradation states. Overall, the potential SOC sequestration in the summer was greater than in the winter grazing degraded grasslands, even degradation levels and restoration managements 
were essentially the same. Summer grazing has been shown to reduce the green leaf area and thus carbon uptake, while grazing during the dormant season only alters soil characteristics such as surface hydrology and aggregate stability (Wolf et al., 2010). This suggested that grazing after plant senescence may have less impact on soil carbon stocks than systems grazed while still growing. Therefore, the loess of soil carbon in summer grazing grasslands was larger than in winter grazing grasslands with the same grazing intensity, and the larger the sequestration potential if improved management practices were adopted. This also suggested that shifting the grassland utilization from summer to winter regime might contribute to soil carbon accumulation.

SOC accumulation tends to decrease with time, as $\mathrm{C}$ stocks reached a steady state in restored alpine meadows after about $15 \mathrm{yr}$. SOC pools at this steady state are not necessarily saturated, because the simulated alpine meadow soil carbon stocks by 2030 are still somewhat lower than the estimated equilibrium before degradation. It is likely that $\mathrm{C}$ pools in a "transient steady-state" are on a path to a saturation behaviour which required hundreds of years ( $\mathrm{O}^{\prime} \mathrm{Brien}$ and Jastrow, 2013). Nevertheless, our findings regarding the SOC sequestration in degraded grasslands over the projection time span are compatible with studies conducted in the Tibetan Plateau. Shi et al. (2009) and Guo et al. (2008) reported that re-sown pastures reclaimed from degraded grassland sequestered soil carbon at a rate of 1.26 and $1.09 \mathrm{Mg}$ $\mathrm{Cha}^{-1} \mathrm{yr}^{-1}$, respectively. The soil carbon sequestration rate in our modelling study showed a similar potential to reported carbon sequestration values of fenced exclosures in which grazing has been excluded (Shi et al., 2009; Guo et al., 2008; Wang et al., 2011). However, it has to be kept in mind that adjustment in stocking rates to avoid overgrazing, rather than grazing prohibition, was used as a management tool in our simulations. Other management practices may compensate for the negative effect of grazing on SOC such as the reduction in $\mathrm{C}$ input to soil. Application of fertilizers, adapted stocking rates and introduction of cultivated pastures may be suitable options for the Tibetan Plateau, considering the economic wellbeing of millions of traditional pastoralists and ecological sustainability.

Our local level simulations could be severe as a reference when estimating possible SOC gains of degraded Tibetan grasslands at the regional scale. Duan et al. (2013) reported that towards the end of last century about $33 \%$ of Tibetan grasslands were degraded to different degrees, of which ca. $16.54 \%$ was extremely degraded. We predicted roughly an annual carbon sink in degraded Tibetan grassland soils of $0.022-0.059 \mathrm{Pg} \mathrm{C} \mathrm{yr}^{-1}$ in the $0-20 \mathrm{~cm}$ depth layer, assuming half of the total degraded area was summer grazing grasslands, which is similar to net carbon sequestration in Tibetan forests $\left(0.024 \mathrm{Pg} \mathrm{C} \mathrm{yr}^{-1}\right.$ ) over the 1980s and 1990s (Fang et al., 2007). This sequestration would be equivalent to 1$4 \%$ of fossil fuel $\mathrm{CO}_{2}$ emissions in China in 2006 (Gregg et al., 2008). However, the magnitude of soil carbon sequestra- tion may be potentially underestimated when only considering topsoil, in view of sequestration capacities at deeper soil depths (Wang et al., 2011).

\subsection{Uncertainties}

Although the parameterizations of the Century model were improved and calibrated against temporal observations of plant growth of a long-term alpine meadow experiment, large uncertainties still remain in our simulation of the soil carbon dynamics due to the uncertainty of forcing data. The climate forcing extrapolated from the meteorological station about $40 \mathrm{~km}$ away from our study area may not well represent the spatial change of climate over the small mountainous region with a large range of elevation (from 3100 to $4200 \mathrm{~m}$ ). In addition, averaging soil characteristics by degradation level obscured the complexities of landscapes. Similarly, the scale of the historic grassland management scenarios utilized contains implicit generalizations that oversimplified the fieldspecific herder's activities because herders often shared limited information about history of fields, especially grazing intensity (Tornquist et al., 2009). Without considering these nuances, uniform grassland management practices could lead to large uncertainty in SOC sequestration at site scale. A spatially explicit simulation of management history in future studies where information about past management is available would help improve SOC modelling (Tornquist et al., 2009).

Another source of uncertainty is related to the propagation of "adjusted" model parameters. Although soil carbon simulations for winter grazing grasslands were conducted, we must emphasize that the model inputs for winter grazing grasslands were based on extrapolation from summer grazing grassland inputs applied. This may have also contributed to some modelling errors. Nevertheless, the similarity between these winter and summer grazing grasslands (e.g. plant composition and soil type), which provides a base for our modelling work, may lead to small uncertainty derived from the propagation of model inputs.

Besides the above mentioned, climate change could also influence the soil carbon balance of the grasslands through altering plant growth and organic matter decomposition (Yang et al., 2009). There is general agreement that the Qinghai-Tibetan Plateau is particularly sensitive to global climate change (Tan et al., 2007; Piao et al., 2012). Various sources provide statistical evidence of a general warming trend on the Qinghai-Tibetan Plateau over the past decades (Liu et al., 2006; Piao et al., 2012). For Zeku County, precipitation trends displayed no discernible change, while temperature has significantly increased over the past three decades (from 1960-1990). Small increases in summer temperatures will improve vegetation growth in this region where growing seasons are short and cold to begin with (Zhang et al., 2013). This resulting increase in carbon inputs may override the temperature-induced rise in soil decomposition 
rates, and consequently SOC would tend to increase (Qi et al., 2011). Considering that short-term climate warming is most likely to benefit SOC accumulation, we speculated that our estimates of carbon sequestration over the period 2010-2030 were conservative.

\section{Conclusions}

We concluded that the Century model described well the behaviour of alpine meadow SOC stocks in 2010 after being calibrated against field data (for the period 1998-2004) of the Haibei Research Station. The simulation of overgrazing implemented by 1960 and extended to 2010 showed a SOC stock depletion. Improved grassland management, such as application of fertilizers, adapted stocking rates, shift of grazing season and establishment of cultivated pasture, led to the considerable soil carbon sequestration by 2030 . The predicted SOC sequestration rates were in accordance with the general sequestration rates given in the literature for Tibetan alpine meadows. Grazing regime adjustment (including grazing intensity and grazing season) and cultivated pasture establishment are potential effective strategies to increase SOC in Tibetan grasslands and could subsequently offset anthropogenic $\mathrm{CO}_{2}$ emissions.

\section{The Supplement related to this article is available online at doi:10.5194/bg-11-3495-2014-supplement.}

Acknowledgements. This study was supported by National Basic Research Programs (2013CB956000), Strategic Priority Research Program (A and B) of the Chinese Academy of Sciences (XDB03030403 and XDA05070205), the National Science Foundation for Young Scientists (41303062), and the West Light Foundation of the Chinese Academy of Science. The authors are grateful of Cindy Keough for providing the Century model version 4.5. We would like to thank the National Field Observation Station of Haibei Alpine Meadow Ecosystem Research Station, the Northwest Institute of Plateau Biology, Chinese Academy of Science, for providing vegetation and climate data.

Edited by: M. Dai

\section{References}

Batlle-Bayer, L., Batjes, N. H., and Bindraban, P. S.: Changes in organic carbon stocks upon land use conversion in the Brazilian Cerrado: A review, Agr. Ecosyst. Environ., 137, 47-58, 2010.

Conant, R. T., Paustian, K., and Elliott, E. T.: Grassland management and conversion into grassland: effects on soil carbon, Ecol. Appl., 11, 343-355, 2001.

Duan, H. F., Zhu, J. R., and Ma, X. J.: Alpine grassland degradation and its restoration and sustainable development on QianghaiTibet Plateau, http://www.paper.edu.cn, 2013.
Fang, J., Guo, Z., Piao, S., and Chen, A.: Terrestrial vegetation carbon sinks in China, 1981-2000, Sci. China Ser. D: Earth Sci., 50, 1341-1350, 2007.

Feng, X. and Zhao, Y.: Grazing intensity monitoring in Northern China steppe: Integrating CENTURY model and MODIS data, Ecol. Indic., 11, 175-182, 2011.

Gregg, J. S., Andres, R. J., and Marland, G.: China: Emissions pattern of the world leader in $\mathrm{CO}_{2}$ emissions from fossil fuel consumption and cement production, Geophys. Res. Lett., 35, LO8806, doi:10.1029/2007GL032887, 2008.

Guo, R., Wang, X. K., Lu, F., Duan, X. N., and Ouyang, Z. Y.: Soil carbon sequestration and its potential by grassland ecosystems in China, Acta Ecol. Sin., 28, 862-867, 2008.

Harris, R. B.: Rangeland degradation on the Qinghai-Tibetan plateau: A review of the evidence of its magnitude and causes, J. Arid Environ., 74, 1-12, 2010.

Huang, Y., Sun, W. J., Zhang, W., and Yu, Y. Q.: Changes in soil organic carbon of terrestrial ecosystems in China: A mini-review, Sci. China Life Sci., 53, 766-775, 2010.

Kemp, D. R., Han, G. D., Hou, X. Y., Michalk, D. L., Hou, F. J., $\mathrm{Wu}$, J. P., and Zhang, Y. J.: Innovative grassland management systems for environmental and livelihood benefits, P. Natl. Acad. Sci. USA., 110, 8369-8374, 2013.

Liu, X., Yin, Z. Y., Shao, X., and Qin, N.: Temporal trends and variability of daily maximum and minimum, extreme temperature events, and growing season length over the eastern and central Tibetan Plateau during 1961-2003, J. Geophys. Res.-Atmos., 111, D19109, doi:10.1029/2005JD006915, 2006.

Luo, Y. Q. and Weng, E. S.: Dynamic disequilibrium of the terrestrial carbon cycle under global change, Trends Ecol. Evol., 26, 96-104, 2011.

Mcsherry, M. E. and Ritchie, M. E.: Effects of grazing on grassland soil carbon: a global review, Glob. Change Biol., 19, 1347-1357, 2013.

Miehe, G., Miehe, S., Kaiser, K., Liu, J. Q. and Zhao, X.: Status and dynamics of the Kobresia pygmaea ecosystem on the Tibetan Plateau, AMBIO: J. Human Environ., 37, 272-279, 2008.

O'Brien, S. L. and Jastrow, J. D.: Physical and chemical protection in hierarchical soil aggregates regulates soil carbon and nitrogen recovery in restored perennial grasslands, Soil Biol. Biochem., 61, 1-13, 2013.

Pei, H. K.: Effect of different grazing intensity on soil nutrient and texture, J. Qinghai Univ., 22, 29-31, 2004.

Piao, S. L., Tan, K., Nan, H. J., Ciais, P., Fang, J. Y., Wang, T., Vuichard, N., and Zhu, B.: Impacts of climate and $\mathrm{CO}_{2}$ changes on the vegetation growth and carbon balance of Qinghai-Tibetan grasslands over the past five decades, Global Planet. Change, 98/99, 73-80, 2012.

Qi, W. W., Niu, H. S., Wang, S. P., Liu, Y. J., and Zhang, L. R. 2012. Simulation of effects of warming on carbon budget in alpine meadow ecosystem on the Tibetan Plateau, Acta Ecol. Sin., 32, 1713-1722, 2012.

Scurlock, J., Johnson, K., and Olson, R.: Estimating net primary productivity from grassland biomass dynamics measurements, Glob. Change Biol., 8, 736-753, 2002.

Shi, F., Li, Y. E., Gao, Q. Z., Wan, Y. F., Qin, X. B., Jin, L., Liu, Y. T., and Wu, Y. J.: Effects of managements on soil organic carbon of grassland in China, Pratac. Sci., 26, 9-15, 2009. 
Tan, K., Ciais, P., Piao, S. L., Wu, X. P., Tang, Y. H., Vuichard, N., Liang, S., and Fang, J. Y.: Application of the ORCHIDEE global vegetation model to evaluate biomass and soil carbon stocks of Qinghai-Tibetan grasslands, Global Biogeochem. Cy., 24, GB1013, doi:10.1029/2009GB003530, 2010.

Tornquist, C. G., Gassman, P. W., Mielniczuk, J., Giasson, E., and Campbell, T.: Spatially explicit simulations of soil $\mathrm{C}$ dynamics in Southern Brazil: Integrating century and GIS with i_Century, Geoderma, 150, 404-414, 2009.

Wang, Q. L., Cao, G. M., and Wang, C. T.: The impact of grazing on the activities of soil enzymes and soil environmental factors in alpine Kobresia pygmaea meadow, Plant Nutr. Fert. Sci., 13, 856-864, 2007.

Wang, S., Wilkes, A., Zhang, Z., Chang, X., Lang, R., Wang, Y., and Niu, H.: Management and land use change effects on soil carbon in northern China's grasslands: a synthesis, Agr. Ecosyst. Environ., 142, 329-340, 2011.

Wang, Y., Zhou, G., and Jia, B.: Modeling SOC and NPP responses of meadow steppe to different grazing intensities in Northeast China, Ecol. Model., 217, 72-78, 2008.

Wolf, B., Zheng, X. H., Brüggemann, N., Chen, W. W., Dannenmann, M., Han, X., Sutton, M. A., Wu, H. H., Yao, Z. S., and Butterbach-Bahl, K.: Grazing-induced reduction of natural nitrous oxide release from continental steppe, Nature, 464, 881884,2010

Xie, Z. B., Zhu, J. G., Liu, G., Cadisch, G., Hasegawa, T., Chen, C. M., Sun, H. F., Tang, H. Y., and Zeng, Q.: Soil organic carbon stocks in China and changes from 1980s to 2000s, Glob. Change Biol., 13, 1989-2007, 2007.

$\mathrm{Xu}$, W., Chen, X., Luo, G., and Lin, Q.: Using the CENTURY model to assess the impact of land reclamation and management practices in oasis agriculture on the dynamics of soil organic carbon in the arid region of North-western China, Ecol. Complex., 8, 30-37, 2010.
Yang, Y. H., Fang, J. Y., Tang, Y. H., Ji, C. J., Zheng, C. Y., He, J. S., and Zhu, B.: Storage, patterns and controls of soil organic carbon in the Tibetan grasslands, Glob. Change Biol., 14, 15921599, 2008.

Yang, Y. H., Fang, J. Y., Smith, P., Tang, Y. H., Chen, A. P., Ji, C. J., Hu, H. F., Rao, S., Tan, K., and He, J. S.: Changes in topsoil carbon stock in the Tibetan grasslands between the 1980s and 2004, Global Change Biol., 15, 2723-2729, 2009.

Zhang, G., Zhang, Y., Dong, J., and Xiao, X.: Green-up dates in the Tibetan Plateau have continuously advanced from 1982 to 2011 , P. Natl. Acad. Sci. USA., 110, 4309-4314, 2013.

Zhang, J. X., Cao, G. M., Zhou, D. W., Hu, Q. W., and Zhao, X. Q.: The carbon storage and carbon cycle among the atmosphere, soil, vegetation and animal in the Kobresia humilis alpine meadow ecosystem, Acta Ecol. Sin., 23, 627-634, 2003.

Zhang, Y. Q., Tang, Y. H., Jiang, J., and Yang, Y. H.: Characterizing the dynamics of soil organic carbon in grasslands on the QinghaiTibetan Plateau, Sci. China Ser. D: Earth Sci., 50, 113-120, 2007.

Zhao, G., Bryan, B. A., King, D., Luo, Z., Wang, E., Song, X., and $\mathrm{Yu}, \mathrm{Q}$.: Impact of agricultural management practices on soil organic carbon: simulation of Australian wheat systems, Glob. Change Biol., 19, 1585-1597, 2013.

Zhao, X. Q., Cao, G. M., and Li, Y. N.: Alpine meadow ecosystem and global change. Science Press, Beijing, 2009.

Zhuang, Q., He, J., Lu, Y., Ji, L., Xiao, J., and Luo, T.: Carbon dynamics of terrestrial ecosystems on the Tibetan Plateau during the 20th century: an analysis with a process-based biogeochemical model, Glob. Ecol. Biogeogr., 19, 649-.662, 2010. 